\title{
Topic-focused analysis in a case of integrative psychotherapy with a father fearing his own anger
}

\section{Introduction}

In the field of psychotherapy, there exists a troubled relationship between research and practice. While most clinicians acknowledge the value of evidence-based practice, they also question the clinical relevance of much research that is published (Morrow-Bradley \& Elliott, 1986; Stewart, Stirman, \& Chambless, 2012). Single case designs are increasingly used in psychotherapy process research as a means of generating knowledge that is relevant to practice (McLeod, 2011). Case study research can be used to document how clinicians in routine practice actually work, and can contribute to the development of practice-relevant theoretical models of change, built up a case at a time (Stiles, 2007). Such a research strategy is particularly important in relation to clinical work being undertaken by therapists who define themselves as eclectic, integrative or pluralistic in orientation, rather than implementing a singular evidence-based approach. In various surveys, a high proportion of experienced clinicians describe themselves as using an integrative approach (Norcross, Karpiak, \& Lister, 
2005) or report using techniques from a range of models of therapy (Rihacek \& Roubal, 2017;

Thoma \& Cecero, 2009). Little is known about what these therapists actually do in their work with clients. As a result, potentially useful knowledge, arising from front-line clinical experience is being lost to scientific inquiry, and is not open to evaluation or able to influence theory and training.

Examining how integrative therapists work with clients with anger issues represents an area in which intensive single-case analysis has the potential to generate new understanding. The investigation of interventions around client anger is a priority for the psychotherapy research community: Anger represents an under-recognised theme within many cases (Cassiello-Robbins \& Barlow, 2016). Client expression of anger is associated with poor outcomes (Henry, Schacht, \& Strupp, 1990), presumably because therapists may feel threatened by anger and/or because clients use anger to ward off interpersonal support in ways that limit their constructive engagement with therapy.

There exists a range of models of how to work therapeutically with anger, for example based on psychodynamic (Josephs \& McLeod, 2014; Ornstein, 1999), cognitive-behavioural (Deffenbacher, 1999) and experiential principles (Paivio, 1999; Pascual-Leone, Gilles, Singh, \& Andreescu, 2013). In a review of research into the outcomes of therapy for anger, Saini (2009) found evidence to support the efficacy of many different types of anger intervention, and offered support for the development of an integrative, multi-component approach (Digiuseppe \& Tafrate, 2001). A task analysis of effective anger resolution events identified two distinct pathways that could be pursued (Kannan et al., 2011). Both pathways started with an explicit focus on the topic of anger and how it occurred in the life of the client. One pathway then reframed anger as an expression of unresolved past events and hidden needs. A key strategy here was development of awareness around the hurt underlying the anger, leading to the client becoming better able to be more assertive about their needs. The other 
pathway focused on enabling the client to apply new strategies for responding to angereliciting social situations in alternative ways, for example using relaxation skills.

Single case analysis makes it possible to explore the ways in which therapeutic processes in anger-oriented therapy unfold over time. Few single-case studies of integrative therapy in clients with anger issues have been published. Kramer, Berthoud, Keller, and Caspar (2014) used a method of individualized case conceptualization that allowed links to be made between current anger issues, early developmental experiences, and client expression of emotion in therapy sessions. A key finding in this good-outcome case was the importance of the development of a sufficiently sensitive level of therapist relational responsiveness that make it possible for the client to allow painful affect to be expressed in session. Other case reports of integrative therapy for anger have underscored the complex meaning of this emotion for some clients, for example drawing on biologically-based explanations (Eatough $\&$ Smith, 2006) and gendered perspectives (Cox \& St. Clair, 2005).

The present paper adds to this body of case-based knowledge of the process of integrative therapy for anger, by presenting a topic-based analysis of brief therapy with a client who identified learning to control his anger as the primary goal of therapy. Topic Change Process Analysis (TCPA) is a qualitative methodology for the analysis of therapy transcript data, designed to provide a detailed descriptive account of the process of therapy in specific cases (Skjerve, Reichelt \& McLeod, 2016) The rationale for this approach is that one type of event that can be observed in all treatment processes is what topics are discussed, what shifts of topics are taking place through the sessions and how the topics are transformed in the client-therapist interaction. Topics can be defined as "what participants are talking about" (McLeod \& Balamoutsou, 2006). Typically, content reflects client issues, such as client family conflicts or therapist agendas related to what the therapist sees as the main client 
problems. Several researchers with different theoretical orientations (Angus \& Hardtke, 1994; Friedlander \& Phillips, 1984; McLeod \& Balamoutsou, 2006; Milbrath, Bauknight, Horowitz, Amoro, \& Sugahara, 1995; Stiles, 2002; Tracey, 1985; Tracey \& Ray, 1984) have categorized the material of audio transcripts from therapies into topics, to explore the therapeutic process. Among the questions studied are how the client and the therapist are interacting in the discussion of the topics, and how this interaction is influencing the meaning and the emotional significance of the topics.

This study is one of a series of case studies aiming at describing topic changes that take place in "practice as usual" integrative psychotherapy and to explore the interaction influencing these changes (Skjerve, Reichelt \& McLeod, 2016; Reichelt, Skjerve \& McLeod, 2017a, Reichelt, Skjerve \& McLeod, 2017b). The intent of the study is threefold. It seeks to further our understanding the treatment of angry patients, and of integrative approaches to treatment. It is also a part of increasing our knowledge of the usefulness of the TCPA approach for analysing qualitative material.

\section{Method}

The case was selected from a database of cases collected for psychotherapy research purposes (Rønnestad, 2009). The database consists of 48 clients being treated by 18 highly experienced therapists, doing "therapy as usual" in their ordinary practices. The present case was chosen for study because it demonstrated an outcome that was reported by the client as being highly satisfactory, had been completed within a limited number of sessions, and reflected the work of a practitioner who was self-avowedly integrationist in orientation.

\section{The Client}


The client, Steve, was a man in his late thirties, seeking help because he feared his own anger. He was married, with three children, and had no previous experience with therapy.

\section{The Therapist}

The therapist was in her middle fifties, with 35 years of experience as a therapist. She described her approach to therapy as theoretically informed by developmental and interpersonal perspectives. In a self-evaluating questionnaire, she reported having incorporated ideas from humanistic therapy, developmental theory, dynamic therapy, behavioral therapy, and systemic therapy. The therapy took place in an independent practice setting.

\section{The Researchers}

We believe that it is useful to locate the approach outlined in this paper, within the conceptual and philosophical influences that have shaped our thinking. For reasons of space, this discussion is necessarily brief. Our theoretical orientation as therapists is eclectic, pluralistic, empirical, pragmatic and collaborative. Many therapeutic approaches, including behavioural therapy, different systemic theories, cognitive behavioural therapy, narrative therapy and the humanistic tradition, have been important orientations in our therapeutic work. We have experience of both qualitative and quantitative research. Our exploration of the therapeutic processes has been empirically derived, rather than being determined by a specific theory; we wished to describe the therapist-client interaction with as few interpretations as possible. Our aim has been to develop a method of analysis that will allow cases to be described. This will make it possible both to compare cases, and to construct a solid descriptive platform that will allow alternative theoretical formulations to be applied.

\section{Context}


The immediate context for the case was a psychotherapy process-outcome study carried out at the Department of Psychology, the University of Oslo. Therapists were free to choose the method(s) they wanted, and most of them were oriented towards some kind of integrationism. The clients were referred to out-patient treatment, mostly from their medical practitioner, for psychotherapy (UU, 2009).

A further important part of the context is that integrationism has been established as a strong tradition within [name of country] through the last 40 years. The most suitable term for this tradition is technical eclecticism, but it is also characterized by an interest in drawing on the various theories underpinning the techniques and common factors. Lately the concept of pluralism (Cooper and McLeod, 2011) has attracted some interest within this professional community. The Norwegian Health System allocates substantial funding to private practitioners (psychologists and psychiatrists) to allow free access to outpatient therapy to a large group of clients. For the time being there are few professional obligations tied to the therapist being publicly paid. For example, therapists may use the therapy method(s) that they prefer, or that they decide are appropriate in particular cases, and keep the client in therapy as long as both parties find it useful.

\section{Measures}

Data were collected from the following sources:

Standardized measures. Therapist and client rated the quality of their relationship on Working Alliance Inventory (WAI-SR; Hatcher \& Gillaspy, 2006) after sessions 3 and 6, and after the final session. The client completed two outcome questionnaires: Inventory of Interpersonal Problems (IIP-C-64; Alden, Wiggins, \& Pincus, 1990) and Outcome Questionnaire (OQ-45.2; Wells, Burlingame, Lambert, Hoag, \& Hope,1996) after sessions 1, 3 and 6 , and one year after the last session. 
Audio-recordings and session transcripts. All sessions were audio-recorded and transcribed (except the pre-interview).

Post-therapy interviews. Client and the therapist were requested - in independent interviews by two different interviewers - to recount their experiences from therapy and reflect upon the outcome and how the therapy process had evolved from beginning to end. Both were interviewed after the end of therapy, and the client additionally 3-4 years after therapy.

\section{Ethics}

The therapist and subsequently her client were recruited using procedures approved by the Regional Committee for Medical and Health Research Ethics. The therapist met with the client once before the first transcribed session, to ascertain that the client wanted to join the project and had the information that was relevant for him to give informed consent. Data were stored according to a licence awarded by the Norwegian Social Science Data services. Details about the therapist and the client have been transformed to provide anonymity.

\section{Data Analysis}

TCPA was applied to all the transcribed sessions. Other data collected on the case quantitative measures and follow-up interviews - were used as a means of contextualizing the primary transcript-based analysis and to evaluate the therapeutic outcome.

Units for the analysis were all the utterances within a session, defined as all verbalizations between two speaking turns. Utterances are the natural unit for examining how participants are influencing each other in the dialogue. Utterances in sequences referring to the same core content were categorized into topics. Utterances were further grouped into two main categories: direct responses, and meta-comments. Direct responses represented some form of continuation or extension of what the other person is saying, for instance exploring 
questions, supporting, arguing or confirming. Through the categorization of responses it is possible to discern repeated constellations of responses, called patterns of interaction. Metacomments comprise reflections on the ongoing content of the dialogue, or introduction of a different perspective on the current issue. Meta-comments typically comprise hypotheses, reframings, ideas, relabelings and interpretations.

To get a picture of topic changes, tables showing the topics in each session and the one that initiated them were developed. Analysis was also carried out on the perspectives developed by the participants in relation to the topics that were explored in different sessions, and of characteristic patterns of interaction between client and therapist, with the intention of generating descriptive information not covered in the categories of topics and responses.

Two of the authors read the transcript and independently categorized all utterances in topics, direct responses and meta-comments. Categorizations were then discussed until consensus was achieved. The aim of the consensus process was not to find the "true" label for topics and utterances. The cooperation in the consensus process was particularly helpful in defining topics that were not overlapping, deciding on what content should be included in each topic, and defining shifts in topics. The agreement of the parties was high.

The formulations of the content of the topics, and the expressions of emotional reactions and viewpoints on the content, were explored to catch eventual changes in the way the topics were conceptualized and experienced. Such topic changes were termed changes in perspective. To limit the amount of data, a short summary of each utterance was written. Responses indicating changes in perspective on topic were noted. The search for consensus of categorization and formulation of perspective changes, and particular patterns of the clienttherapist interaction, constitutes a "hermeneutic circle" (Laverty, 2003; Rennie, 2012), 
moving back and forth between the material and descriptions of perspective changes and interaction patterns.

To illustrate the response categorization, an example of transcript analysis is included:

TDR (Type of response): Therapist direct response

CDR (Type of response): Client direct response

TMC: Therapist meta-comment

In italics: The utterance or an abbreviated version of the utterance

Excerpt from session 4, page 31 of the transcript. The ongoing topic is "Child rearing", and Steve had told a long story about an episode when Bill [his son] had been taken to his room for screaming at dinner. He immediately said he had stopped and was allowed back again, and then he started to scream again, and this went on. Steve said that he was on the verge of losing control.

TMC: When Bill stopped screaming and began anew, I don't think he tried to trick you. He is still using his old reaction patterns.

CDR (confirming): I believe you are right.

TDR (suggestion): I think it is important to take him out of the room anyway, then he can come back if he wants to.

CDR (confirming): I did that the second time.

TDR (underlining): I think it is good for him that just that principle is carried through.

CDR (confirming): Yes

TDR (exploration): How did you say it the second time? 
CDR (accounting for): When Bill said "now have I stopped”, I said that he hadn't, and that he had to leave the room with me until he was quiet. But the he went into the hall and screamed, and I did not know what to do.

Further examples of direct responses and meta-comments can be found in the Results section below. Appendix A provides a summary outline of the various steps in the application of TCPA

\section{Results}

The findings of the case analysis are presented in the following sections. A summary of the case is followed by a description and analysis of topics and topic shifts, exploration of changes in topics and changes in perspectives on topics, and patterns of interaction between client and therapist.

\section{Case Summary}

Steve was a man in his middle thirties, married and with three small children (two boys at four and seven and a daughter at 2), who sought therapeutic help because he experienced that he could not control his anger towards his children. He did not become violent, but felt that he abused them verbally in a way that scared them. He worked in an organization for child care, had a background working in the field of education, and had strong bad feelings about not being able to live up to his own standards. Even though his wife also had problems handling the children, and they often quarrelled about them, he felt that his anger basically was his problem. Steve had a minor physical handicap, a small limp, that he believed had influenced his ways of coping with social relations through the years. He was, however, a very agile and strong man. 
The therapist and the client had 13 sessions alone, and this analysis is based on the 11 sessions that were transcribed. The first represented an introduction to and the establishment of an agreement to join the project, and the $12^{\text {th }}$ was not taped due to a mistake. Additionally, the couple had two sessions with the therapist mainly about problems handling their middle child, Bill, that were not taped.

The therapist and Steve were interviewed after the end of therapy. They were very satisfied, both with their relationship and the treatment results, and emphasized that anger did not appear to be Steve's problem. He was in a stressing life situation and overwhelmed by the challenges of a tough working situation, experiencing a deep sense of hopelessness. During the therapy he developed tools for coping with the challenges, which represented a great relief for him. Steve clearly expressed that he got just what he wanted, at this point defined as problems connected to his handling of Bill, but also a feeling that talking so thoroughly about his life had opened up some new issues that they might have worked with. These were not clearly specified, but seemed to be related to earlier life experiences and difficult feelings about his parents. Such reflections arose after the end of therapy.

Data from session evaluation forms showed a very high score on the alliance forms, and highly significant positive changes on both questionnaires. The client ratings on WAI were 6.75 and 6.42 after Session 3 and 6, and 6.00 after the end of therapy, and the therapist scored 5.0, 5.83 and 5.17 at the same points of time. These scores are within the top $10 \%$ of cases within the overall project sample. The scores from the IIP-64 were 0.88 at the beginning of therapy, 0.52 at the end of therapy, and 0.20 at the follow-up interview. The scores from OQ45 were 65.45 at the beginning of therapy, 35.80 at the end of therapy, and 19 at the follow-up interview.

\section{Topics and Shifts in Topics}


Tables 1, 2 and 3 show the topics occurring in each session, their frequency of their occurrence, and the participant that initiated the topic. The order of the topics in these tables are in accordance with how they are presented in the narratives.

\section{Description of Topics}

\section{Insert Table 1 about here}

A large proportion of the content of the sessions was connected to family life. Even though Steve talked a lot about reactions to his wife, their conflicts, his relation to the other children and their relation to each other, Bill was his central focus of concern. As Steve said in the interview: "If Bill had not been as he is, I would never have contacted a psychologist." The issue was not only Steve's emotions related to the handling of Bill and their influence on Steve's emotions in handling family life, but also more generally Bill's deviant conduct and questions of how he should be brought up. Although these issues were intertwined they had different implications for therapeutic interventions. We have therefore differentiated three topics related to family life: "Feelings related to the family" (reactions towards his wife, siblings and general family matters), "Child conduct" (Bill's behaviour) and "Child rearing” (Steve's handling of Bill). Another concern explored in therapy was Steve's job. It was related to children, and in spite of many satisfactory aspects it represented stressing elements such as heavy work, time limitations, and reminder of his standards for child upbringing that he did not fulfil at home. "Feelings related to job" was identified as a fourth topic. Experiences from the past were also touched on as concerns related to Steve's emotional problems today, as the topics "Feelings as a child and adolescent" and "Feelings related to parents". The topic of "Process" covers remarks, evaluations or comments on what they are working on at the moment. In this therapy both participants are talkative and associative, and discuss other matters than concerns, like principles of education in the school today. We have 
labelled these exchanges "Small-talk". More complete accounts of each topic are covered in a later section.

\section{Topic Shifts}

Insert Table 2 about here

Insert Table 3 about here

Shifts of topics were numerous in this therapy, particularly from session 3 to session 7 , and they varied from nine to 29 shifts in each session. The total number of shifts was 185 . The sessions usually began with the therapist asking a process question such as "how are you today concerning what we have been talking about", followed by a general utterance from Steve such as "I have been quite exhausted this week", and stories about concrete episodes related to his exhaustion and concerns. The topic "Feelings related to the family "recurred in every session, and were closely associated with "Child rearing" and "Child behaviour". The high number of shifts did not make the therapy appear illogical or fragmented, but rather appeared to arise as a consequence of a spontaneous and associative client interacting with a therapist giving him much space for recounting his experiences and structuring him through integrating the relevant topics with his stories. For example, the therapist introduced the topic of "Child conduct" when Steve expanded on his bad feelings about the disturbances Bill caused in family life, to initiate a different focus.

Even though Steve initiated topics much more frequently than the therapist, the therapist had a high number of initiations. In addition to their function as a structural tool, they gave her space to develop her therapeutic interventions. When Steve for instance was telling a long story about Bill's deviant behaviour, she might focus on how his behaviour influenced Bill's feelings and initiate a conversation based on differentiation of feelings. 
The therapist was much less active in the work on the topics during the last sessions of the therapy, even if Steve continued to bring them up. She appeared to be assured that Steve was changing in a satisfactory way. After session 6 she did not initiate the topic of "Feelings related to the family", and in session 7 and 8 she did not initiate the topics of "Child rearing" and "Child conduct". The last two topics were, however, initiated several times in session 9. We know from the analysis of topics that Steve brought these topics up again in session 9, and conveyed that he was satisfied with what they achieved in that session. Steve also initiated fewer topics in the last sessions, and talked much about his progress.

The topics that focused on family appeared to have been the most significant aspects of therapy for Steve. He, however, initiated the topic of feelings related to work 13 times, in six sessions. The therapist only initiated it twice. Even though his negative reactions at work appeared similar to those at home, he felt appreciated at work and could control his reactions to a larger degree.

They did not spend much time on the topics concerning the past. Discussions around childhood and youth were initiated by both, in the context of family topics, but not explored or expanded on. Steve's feelings for his parents were mostly initiated in response to a crisis in the family, but not related to his present concerns.

Steve initiated small-talk altogether 29 times, in all the sessions apart from the first two. The themes were almost always spurred on by association to a topic they were involved in, and contained concrete episodes, reactions to societal practice and ideals concerning several issues. These passages were often long, and he showed strong engagement in them. The therapist might just listen, or engage in a conversation revealing her own points of view. Only once did small-talk appear to be a diversion from a difficult issue. The therapist always 
interrupted the small-talk through initiating a topic. The therapist only initiated small-talk three times, in the form of conventional phrases, and interrupted herself every time.

The process topic was initiated 17 times by the therapist and five by Steve. Process responses served mostly as a way of structuring therapy, for instance by enabling the therapist to initiate a focus at the beginning of sessions and summing up at the end. This topic also included examples of client and therapist evaluation of the progress of therapy.

\section{What the Topic Shifts Tell us about the Therapy}

Read superficially, the high number of topic initiations and the associative and storytelling style of Steve (closely followed by a patient therapist who rarely interrupted him) could be described as an unstructured therapy running its own course, dominated by Steve's bad experiences through the week rather than by explicit goals and tasks. This description was strengthened by the amount of small-talk.

| The analysis of the topic shifts gave a different story about the therapy. The therapist pursued the main topics (those related directly to the problems with Steve's feelings related to the family and to the concerns with Bill) systematically, and created a space for therapeutic interventions. She was the first to initiate the topic of child conduct, which appeared to be helpful in reducing Steve's feelings of guilt about his own behaviour towards Bill. All the other topics were first initiated by Steve. When she intervened (for instance through a topic shift or a meta-comment) she developed a mutual conversation grounded in her own ideas, and Steve responded eagerly and creatively to her initiatives.

The therapist did not engage as much as Steve in talking about contextual issues such as job and past experiences. She never initiated the job topic or the parent topic, and though she might ask him whether he recognised his feelings today in experiences from childhood and youth, these topics were not pursued closely. Even though these topics did not get much 
attention, the narratives of the topics will show that they were not neglected. However, the therapist's primary focus mainly remained on the problems presented in the beginning of therapy.

\section{Narratives of Topics Development through the Psychotherapy Process.}

Analysis of changes in the client's perspective of each topic made it possible to develop a more detailed understanding of the change process.

Feelings related to the family. As strong anger and angry outbursts, particularly directed against his four year-old son, Bill, but also against his wife, were Steve's main reasons to contact the therapist, it may be surprising that anger was not defined as a topic. The reason is that the therapist already from the second session worked on differentiating Steve's feelings and his thoughts related to these feelings. It soon appeared that cognitively telling himself "I can't do this" (in the sense of an aggressive act being disliked by others or against his ethical principles) triggered angry outbursts, while "I don't manage the situation" made him feel depressed and helpless. In session three, the therapist suggested that the selfinstruction "Bill is a small and challenging child, and you should share the burden" might make Steve more optimistic concerning change than "I can't do this", and open him for alternative solutions. Steve responded positively to this suggestion. At this point the therapist offered a meta-comment implying a redefinition of his anger: "I understand your feeling of reacting too strongly, but do not believe that your reaction is based on anger. Your belief that 'I can't do this' mobilizes opposition, not anger. You mobilize energy to fight the feeling of hopelessness. You are a fighter against hopelessness." Steve had some resistance against this redefinition, but the therapist repeated it persistently several times in various ways and in relation to different contexts, and later in the session Steve thanked her for the word "hopelessness". The therapist helped him to identify his strategies for fighting hopelessness, 
and added that she wished that he could, as an adult person, be more comforting and supporting of himself and thus diminish the impact of his "I can't do that" self-statements

In the following sessions, Steve gave several examples of how he had been able to use his new understanding of himself. Defining his reactions as hopelessness rather than anger had helped him to behave more acceptingly towards Bill, and he had started to differentiate between situations where anger was appropriate and where it was destructive. Steve gradually started talking about other emotional issues that influenced family life.

He became more reflective about his own behaviour, and talked about his dependency on routines and orderliness, his irritation about messiness and his wish to always be tidying up. After an account of a typical episode, involving his wife, he had told her about his feelings of hopelessness. The therapist meta-commented: "You tidy up, fix things and this is also a way of handling your own sadness. Nothing wrong about that, but good to know about it and feel friendly about it." Steve: "That is true, but I feel that now I am tidying up in a different way, I am more reflective."

Steve had also reflected on his problems with transitions between different situations. He used to hate coming home from work and into the mess of a house, and had created a small space for himself (changing clothes etc.) between bicycling home and meeting the family. He had also become less strict with himself, being more relaxed regarding his own demands for being a perfect householder and "always the nice guy."

Steve's anger had been a source of conflict between him and his wife. Defining it as hopelessness made it easier for Steve to talk about his feelings rather than acting out his anger. He became more reflective about his sensitivity for what he conceived as reproaches, and attributed it to parental demands for perfection. Steve told many stories about negative episodes between him and his wife, but the therapist did not expand on this issue. She chose 
to invite them together, and Steve's comments on these two sessions were positive. Towards the end of the therapy he expressed expectations of the two of them managing to improve their relationship as well as rearing their children together.

Child conduct and child rearing. It was easy to distinguish between these two topics in the transcripts, but they were intertwined in a way that made it natural to combine them in the same narrative. In most sessions, Steve told long stories about negative aspects of Bill's conduct, that were more focused on how he behaved, and why, than on how to deal with him. The focus was mainly on his uncontrolled, oppositional and unsocial behaviour, but also on his soreness and feelings of despair, his sensitivity, care for babies and animals, and inventiveness. Steve commented that Bill was similar to himself in many ways, particularly in his opposition, but still could not understand why he behaved as he did. The therapist responded by normalising and supporting responses, and also used some psychoeducation to reframe Bill's conduct. A typical sequence from the first session:

Therapist (normalising): I am not worried about Bill.

Steve (showing ambivalence): Maybe not, but we have been somewhat worried.

Therapist (reframing): I think that he represents a particular challenge, having more difficulties in shifting attention from one thing to another than your other kids. He also has problems shifting if he has believed that something would happen and something else happens. At times, he needs help in shifting focus. It might be helpful to focus on routines rather than explanations.

Steve (confirming and showing ambivalence): We haven't been good at this, but his conduct is somewhat unbelievable. 
Therapist (normalising): It is very much like any four years old, easy to explain too much because they talk so well.

After this intervention, Steve became increasingly reflective about family routines and Bill's problems with transitions, and his own ways of handling him. He also suggested other influences on Bill's conduct, as a strong need for mother, jealousy of his siblings, and his vulnerable and intense personality. The therapist asked him if he could recognise that Bill's anger was a fight against despair (a main element in Steve's own feelings in the family), and he agreed with this perspective.

Related to Steve's worry about Bill's lack of control and his “deafness” when Steve tried to stop him, the therapist developed a reframing: "Bill is perfectly able to make plans for himself, his resistance to your plans and his 'deafness' when you try to fit him into yours is due to a collision with his own plans." At first, Steve didn't pick up this point, and talked about a frequent problem (Bill running out of the house in the mornings when Steve went down in the basement to get his boots). The therapist asked whether it would make any difference if Steve said "now I go down to get the boots, what is your plan?" Steve confirmed this. The therapist underlined her point: "Then focus will not be on "you must not go out", because then he must go out." As described in the narrative of "Feelings related to the family "this is also one of Steve's main difficulties. Steve accepted this point, and continued to use the concept "plan" both in understanding Bill's behaviour and in interacting with him. In a later session, Bill had developed a screaming-pattern, which Steve explained as "I think it is about disturbance of his plan, of the schema he has in his head about what is going to happen now."

When Steve talked at length describing his difficulties in coping with Bill, the therapist offered small suggestions while listening. She often underlined the importance of 
routines, particularly in the morning with limited time, to ensure that Bill knew what would happen at points of transitions. She also suggested that Bill might need more routines than the other children in daily situations, such as eating and going to sleep. She helped Steve to find means of behaving consistently when he had to stop acting out behaviour, and advised him to be sure of having Bill's attention before he tried to shift it. "Actions rather than long explanations" was repeated in different ways, as well as the point that the parents should take turns in being responsible for breaking Bill's negative patterns. Steve was very receptive to her suggestions.

In session 11 Steve announced: "Something must have happened to Bill. He still has his small things, but we help him out of them, and it works fine. He shows less anger, and don't get stuck". They talked about how having learnt how to use language to get a "reflection room" might have been important for his development. In session 13 Steve was still satisfied. Some conflicts had occurred, but they had easily managed them. Neither Steve nor his wife were worried about Bill's conduct any longer.

Feelings as a child and adolescent. Early in the second session Steve accounted for how tired he was after a strenuous period with much illness, demanding children, and a quarrel with his wife. Last weekend he had felt very depressed, and had blamed his parents for his reactions. He had remembered phantasies of his childhood, playing with thoughts about suicide to punish his parents, being the martyr that became the hero, the guy with a small physical handicap who won the princess. To compensate for this handicap Steve had become an entertainer among his friends, enjoying being in the centre of positive attention. The therapist did not explore Steve's anger against his parents, and when his parents were brought up in later sessions Steve talked about them in a controlled way. They had been strict, with many rules about what he "must" and "must not" do, and he recognized his own tendency to say "no", before he had thought about the request as a heritage from his father. 
The effects of Steve's physical problem were a topic in several sessions. In session 7 the therapist pointed out that although he might tend to diminish its significance, his handicap had been influential in his accomplishment of developmental tasks. Steve replied: "I have reflected after our talks, and believe that I have used much more energy than I have admitted through the school years, particularly in mastering things and being appreciated. I may be more dependent than many others in that matter, but less today because I'm certain of doing a good job." The issue was brought up only once more, in one of the last sessions, and Steve confirmed his relaxed attitude to it.

Feelings related to parents. This was only a topic in three sessions $(8,10.13)$. As mentioned in the previous section, Steve had talked about his parents having been strict, particularly his father, who always wanted things to be "his way". But he also talked about leniency, and his surprise around getting increased freedom when he got older. Father, however, still had commented on his behaviour when they were with other people. He resented Steve's unconventionality. A couple of years ago Steve had told him to stop doing this: "a man of 35 years is responsible for his own behaviour."

His parents had a very different child rearing style than Steve and his wife, and they resented the way his parents treated their grandchildren. They had had lots of arguments about this, with strong feelings involved. His wife, particularly, did not like the parents to babysit. Steve had felt triangulated by his wife and his mother, but recently he had felt that this triangle had loosened up, and he felt more relaxed and felt very relieved. When the therapist explored this, Steve said: "I am more able to look at my mom, and talk quietly without feeling the triangle mom, wife, me, it is as if the triangle has disappeared. We communicate well, I have contacted her more often (sniffling)." This was not further explored. When Steve talked about these issues he often referred to how experiences with his parents had influenced his 
behaviour towards his own children, but he did not appeal to the therapist for help in relation to this issue

A main concern for Steve was that his father was in poor health. Steve felt guilty about not showing enough empathy toward his father: he reported that he felt "blunt" about it. The therapist explored father's way of talking about his illness, and offered a meta-comment: “It seems like a complaint combined with "I'll manage, don't think about it", that makes it difficult to show empathy." Steve confirmed this interpretation and expanded on it. Once father cried and showed his anxiety, and then Steve had no problem responding in an empathic way.

They then talked about Steve's needs for directing his own life, making his own choices, and how these strong needs had roots in his relation to his parents. He also reflected that his attitude "I can't do this" arose from negative experiences with his parents, and also his wife, and that he felt that the word "hopelessness" could help him to refrain from reacting strongly to their demands. If he responded to "I can't do this" by redefining the feeling as hopelessness, alternative ways of reacting would be mobilized.

Feelings related to job. Steve described himself as a good child-care worker, enjoying his job very much. His main problem was emotional reactions to his colleagues, particularly related to demands ("you must") and experiences of being degraded by them. He described himself as fighting his tendency to show his anger at work. The therapist redefined his anger at work as hopelessness (similarly to her way of reframing his anger at home): “I experience that the resistance you mobilize is not very aggressive, and that it is preventing you from being overwhelmed by hopelessness." The therapist also referred to the strategies Steve had developed when he felt degraded as a child and adolescent, using much energy to present himself as a person who didn't mind being teased. They cooperated in developing an 
image of Steve as a sharp, quick-witted guy, responding to experiences of being discounted by others by verbally responding quickly and effectively. At this point, Steve began expanding on his strong sense of responsibility at work- maybe too strong. He offered often to take on tasks, and the administration gave him tasks.

Towards the end of the therapy Steve recounted various stories about his job, around the theme that he had improved his relations to his clients through giving more attention to positive behaviour, but was still being too emotional with his colleagues. He had, however, had a talk with the leader of the institution, who told him that he had changed and was very different. He was more quiet, balanced and still engaged. After telling this Steve told about many good feelings these days, particularly related to control of emotions It seems reasonable to suppose that although Steve had changed behaviour at his job, it was still important for him to tell the therapist about his negative experiences.

Process. The therapist often opened the session with an open-ended question, such as “Where are you now?" Steve might respond with talking concretely about a topic, with metacommunication on his situation, or with evaluation. The therapist followed up whatever he replied, they both meta-commented on his situation and the significance of the therapy, and toward the end they had many evaluative sequences. Steve expressed gratefulness for the therapy, and was concrete in describing how he managed things better.

They also had a couple of process-sequences, initiated by the therapist, on the issue of whether this kind of therapy was sufficient for Bill. Might he need something else? This issue was not mentioned after the fifth session.

Small-talk. The topic was almost always initiated by Steve and the content usually in line with the topic they had been talking about. The small-talk appeared to be triggered by associations to the on-going topic, as his views of child rearing, of school education and 
general aspects of his job situation. He presented views on these topics and own values that were oppositional to cultural "correctness", often as anecdotes that he had recently experienced, and the therapist often joined him in discussions of these issues before she gently lead him back to the topic that was interrupted. Only once did the small-talk appear to represent a way of avoiding focusing on a core therapeutic topic.

In previous case analyses we have conducted, small-talk did not appear as a topic, and we wondered about why the therapist in the present case accepted Steve's chattering and even participated in it. It might have been politeness, but it might also have been a sensitivity to Steve's needs to vent and get credit for his strong opinions and idealism. The therapist appeared to have no problems structuring therapy and directing it towards topics that were productive.

\section{Summary of Changes in Perspectives on Topics}

Feelings related to the family. Steve developed a strikingly different perspective on his feelings in the family context. He stopped regarding himself as an angry person, but as a person overwhelmed by a feeling of hopelessness trying to cope with a demanding child. $\mathrm{He}$ adopted the therapist's definition of him as "a fighter of hopelessness", using his aggressive energy to mobilize alternative ways of treating his child. He became more accepting both of himself and Bill

Child conduct._Steve feared that something might be wrong with Bill. Through the therapy he developed the perspective that Bill was a healthy four year old boy, in some ways a bit younger and in some ways a bit older than his age. He saw strong similarities between himself and Bill, not least in the characteristics that made it difficult to cope with him. 
Child rearing. Steve entered therapy with the perspective that it was impossible to rear Bill, and left it with the perspective that this was a task that he and his wife could manage well.

Feelings related to job. Steve was rather satisfied with his capacity at work, but perceived himself as somewhat unbalanced and emotional (angry) in relation to colleagues. After the therapy he had a more benevolent perspective on himself, which was supported by his boss telling him that he was more quiet, balanced and still engaged.

Feelings as a child and adolescent. This was not a salient issue for Steve, but he left the therapy with a new understanding of the ways he had compensated for his minor physical handicap, along the lines that he had been more vulnerable than he had assumed. He believed that the certainty of doing a good job had made him less vulnerable.

Feelings related to parents._It is difficult to know whether Steve developed new perspectives on this topic, but our impression is that he strengthened and clarified his story about the implications of being the son of his parents.

Small-talk. Being met with understanding and respect from a reputed therapist in regard to a variety of matters of concern to him, may have added to his increased acceptance of himself.

\section{Characteristic patterns of interaction}

Categorizing each utterance in terms of response types made it possible to identify recurring patterns of interaction through the therapy. These patterns illustrate the way the client and therapist worked together and how the work reflected the personal style and resources of each of them. 
Therapist giving and taking space. Steve was a very talkative person. He varied between telling long and detailed stories about concrete happenings at home and in his job, and sharing his thoughts about children and education. His emotions were often strong in recounting the happenings, and he was very associative. The therapist listened to his narratives without much interruption, mostly with “mhm's", but also more actively with repetitions, small comments, and supportive utterances. When the content was in line with the therapist's own ideas, she became more active, repeated earlier relevant suggestions, metacommented or underlined what the client said. At times Steve would stop himself and metacomment on his topic or offer a new topic, and at times the therapist would offer a metacomment as an introduction to an analysis of the events that Steve had been describing.

Involvement. At several points in the therapy both parties became very involved and engaged. This often happened when the therapist had suggested new ways of thinking and acting. They entered a discussion of implications of these suggestions, and often interrupted each other, at times talking both at once. The atmosphere was friendly, and these discussions often ended with developing new ideas about handling the situation.

Repetition of therapist messages. The therapist might seem passive and listening in long periods, but she appeared to have clear agendas for how to help Steve. One example of this was her redefinition of his anger as a feeling of hopelessness. Such redefinitions, and also concrete suggestions of ways of handling challenges, were developed and repeated several times through therapy, until Steve had adopted them as his own. They represented "a red thread" through a therapy characterized by Steve's associative style.

Circling around developmental questions. Steve was concerned about whether Bill's behavior was deviant in ways that demanded particular expert attention. The therapist, who had much knowledge of developmental issues, shared his concern, but chose to regard 
him as a four years old boy who primarily needed particular parental attention related to normal problems. She shared her developmental knowledge with Steve, normalized his problems, and they cooperated in finding ways of helping the parents out of vicious circles. Steve expressed a wish that the therapist should see Bill by himself, but the therapist argued for rather bringing the mother in to help the parents to support each other when confronted by Bill's provoking behavior. Steve assented to this.

A focus on resources. Steve would often begin the sessions by relating stories about Bill's recent provoking behavior. After listening to these stories the therapist might offer comments on how rarely such episodes occurred, on concrete examples of how well the parents generally managed him, and on how Bill had his own plans for what he would do rather that behave impulsively. Many of these comments represented meta-comments reframing the behavior of those involved in a positive way, and Steve mostly accepted them and expanded on them. Gradually he would offer stories about how Bill had improved, and of having fun with him.

\section{Discussion}

The present paper offers an example of a type of case study report that seeks to construct a descriptive account of the process of therapy in a particular case that is accessible to readers from any theoretical orientation.

A key methodological feature of the present study, compared to other therapy case studies and process studies, is that the analysis that was carried out did not rely on therapist self-report, or on coding schemes based on constructs derived from theories of therapy, but sought to describe what happened with as few theoretical inferences as possible. The aim of the study was to describe the process that could be observed in a case of integrative therapy, 
with the broader objective of contributing to the development of an understanding of integrative practice that was grounded in what happens in everyday therapeutic work.

In the following discussion, some central findings will first be pointed out and commented on. The relevance of the findings for an understanding of an integrative approach to therapy for anger issues is then examined. It is important to bear in mind that the material from this case analysis could readily be discussed from other theoretical perspectives than we have applied. Finally, strengths and limitations of the method will be discussed. The design used in this case study does not allow us to conclude that the therapist interventions, or other aspect of the therapeutic process, caused the observed client changes. From the perspective of Micro-analytic Sequential Process Design (Elliott, 2010), in the design applied in TCPA, three key conditions for causal inference are fulfilled (Haynes \& O’Brien, 2000): therapist response is preceding the client response (we know the order of the utterances), covariation between therapist and client responses can be detected, and plausible explanations for the observed relationships can be given. While Haynes and O'Brien required that an explanation should be given in the form of a theory being tested, in this paper the plausibility of the explanation is grounded in the hermeneutic analysis of the therapeutic process. The microanalytic design gives no control of external influences of the therapeutic outcome, the fourth requirement of Haynes and O'Brien (2000). But no such influence (e.g., changes in life circumstances) that plausibly could lead to Steve's changed way of thinking and behaving is known. It therefore seems reasonable to presume that the changes are mainly due to the impact of the therapeutic process.

Both the topic analysis and the interviews after the therapy pointed to a strong common involvement, mutual acceptance and enjoyment of working together. These findings are supported by the high scores on the WAI. No ruptures in the relationship were discerned.

This was observed in all the cases we have analyzed so far (Reichelt, Skjerve \& 
McLeod,2017; Reichelt, Skjerve \& McLeod, 2017, and may be typical for short-time therapy carried out by an experienced therapist within an integrationist and resource-oriented frame.

Goals and tasks of therapy are considered an important part of forming a working alliance (Bordin, 1994). A formal discussion of these issues did not occur, and remained implicit throughout the therapy. We observed the same in both the cases we worked with previously (referred to above), and suggest that indirect, nuanced explorations of client goals may be usual in "therapies as usual" among experienced therapists (Oddli, McLeod, Reichelt, \& Rønnestad, 2014). This is an issue that deserves a closer inspection from researchers.

The client was talkative and associative, and initiated all the substantive topics that formed the basis for the process of therapy. The therapist followed him closely, and structured the therapy through re-initiating topics previously brought up by the client in the session, and repeating responses that she clearly experienced as productive in bringing the therapy forward. She gave him much time to talk without interruption, but had her own agenda for input of information, redefinitions and perspectives that she believed would be helpful for him. A main theoretical perspective in her integrational work was developmental psychology, and her attitude to the client was "client-directed" with focus on client resources, as described by Duncan and Miller (2000). Her concrete work mainly appeared inspired by behavioral parent counseling (Forgatch \& Patterson, 2010), cognitive behavioral work and psychoeducation.

The client had changed significantly, both on quantitative measures and as evaluated on basis of the qualitative analyses. These changes are confirmed in the interview at the end of therapy. The topic analysis demonstrated change in perspectives on all the topics, that can 
be summed up as a more positive self- image and increased ability to reflect on his own actions:

The process that was observed in the case of Steve makes it possible to identify how different aspects of anger may be addressed within an integrative approach to therapy. Early in the therapy, Steve accepted the redefinition of aggression as a fight against hopelessness, and during the therapy he developed an increased experience of mastering a range of strategies for preventing aggression and furthering competence in important interpersonal tasks. These tasks were primarily related to his children and his wife, but also to his job and his parents. These aspects of the case illustrate the capacity for an integrative therapy to encompass both issues of underlying hurt, and the development of new skills (Kannan et al., 2011), rather than regarding these as different pathways or options. The observation that Steve chose not to explore the early childhood origins of his hopelessness, and that his therapist was responsive to this preference, suggests that a client-directed strategy may be valuable for clients whose anger comprises multiple components. The willingness of the therapist to remain focused on anger-related topics, rather than deflect into other issues, reinforces findings from Henry, Schacht, and Strupp (1990) and Kannan et al. (2011) that therapist resoluteness may be a key factor in effective work in the area of anger. A further significant aspect of this case was that anger was consistently explored in context (family and work settings) rather than being defined as a problem within the client.

A striking feature of this therapy was the extent to which the therapist pursued multiple strategies for strengthening client agency (Hoener, Stiles, Luka, \& Gordin, 2012). At the beginning of the therapy the client told long stories about being overwhelmed and helpless. He increasingly began talking about his reflections on such events, and conveyed ideas about how to solve them. These reflections helped him to achieve more emotional control in relation to the persons involved in his tasks, and to gain more independence from 
his therapist concerning how to handle challenges. He also became less dependent on being in physical control of his surroundings, tolerating messiness to a much higher degree. Therapist interventions highlighted the resources of both the father and the child he worried about. She redefined in a positive way, reframed, normalized, and helped Steve to identify and make use of the resources that were available to him. Enhanced agency may be regarded as underpinning the therapeutic work around both life history (Steve's sense of hopelessness) and practical coping dimensions of this case.

Taken together, the findings of this case are highly consistent with the ways in which clients describe positive outcomes, in the context of qualitative interviews carried out after the end of therapy. Moltu et al. (2017) found that clients described themselves as having used dialogue with their therapist to develop new coping strategies and a deeper sense of acceptance of aspects of self, which then made it possible to be resolute in facing up to life situations and issues that had previously been avoided. The process of purposeful engagement with issues was informed by feedback from other people with significant roles in their everyday life. The case of Steve demonstrates how these outcomes can emerge from a flexible, client-directed integrative therapy process.

A limitation of this study is that the researchers defined the topics, and that the participants in the therapy may have had different ideas about the main concerns. The interviews one year after the therapy, however, proves that both parties indirectly confirmed the relevance of the topics. Another limitation was the use of transcripts. Some nonverbal information was written down (as snuffling, laughter etc.), but we may have missed important nonverbal aspects of the interaction. It may also be considered a limitation that the client was highly reflective, taking responsibility for his anger problems. Obviously, not all angry clients would profit by the applied therapeutic approach. On the other side, this may be considered an advantage, illustrating the variety of patients with anger and the usefulness of tailoring 
treatment to the characteristic of each particular person. Finally, we have only knowledge of what the therapist did, and not about how she conceptualized what she did. After reading the paper, the therapist, however, conveyed that she found it interesting and rewarding to read. She did not feel criticized or misunderstood as therapist, and did not think that the client would either.

TCPA is an instrument focusing on observable elements in therapeutic interaction, favouring description rather than interpretation. It is simple, and has similarities with behavioural analysis. It could be combined with other instruments to bring in more nuanced information of the interaction, and hopefully other researchers will find this interesting. The purpose of the TCPA project has been to explore the usefulness of description of therapeutic sequences for pinpointing particular aspects of therapeutic interaction. We want, however, to underline that our own theoretical stance is of great importance for how we have shaped the descriptive data.

\section{Concluding comments}

The evidence from our descriptive, topic-focused analysis of three cases of good outcome integrative therapy carried out by experienced clinicians suggests that this type of therapy can be primarily characterised as based on therapist flexibility in tailoring their interactional style to that of the client, along with a willingness to be persistent in retaining a resolute focus on the expressed concerns and therapeutic priorities of the client. These integrative therapists were actively engaged in structuring the process of therapy, communicating their understanding of the client's problems and how they can be resolved, and affirming the resourcefulness and agency of the client. These therapists were able to facilitate a range of change processes, including cognitive insight, emotion processing, behavioural change, and family restructuring. These cases therefore make it possible to begin 
to identify some of the distinctive features of integrative therapy, at least as it is practiced by therapists within one specific professional community. Further research is required to determine whether other configurations of contemporary integrative practice can be identified, and to explore the limits of this approach, for example in relation to work with hard-to-treat clients or clients with particular disorders.

\section{References}

Alden, L. E., Wiggins, J. S., \& Pincus, A. L. (1990). Construction of circumplex scales for the inventory of interpersonal problems. Journal of Personality Assessment, 55, 521-536. doi: $10.1080 / 00223891.1990 .9674088$

Angus, L., \& Hardtke, K. (1994). Narrative processes in psychotherapy. Canadian Psychology, 35, 190-203. doi: 10.1037/0708-5591.35.2.190 
Bordin, E. S. (1994). Theory and research on the therapeutic working alliance: New directions. In A. O. Horvath \& L. S. Greenberg ( Eds.), The working alliance: Theory, research and practice (pp. 13-37). New York, N.Y: Wiley.

Cassiello-Robbins, C., \& Barlow, D. H. (2016). Anger: The unrecognized emotion in emotional disorders. Clinical Psychology Science and Practice, 23, 66-85. doi: 10.1111.cpsp. 12139

Cooper, M., \& McLeod, J. (2011). Pluralistic counselling and psychotherapy. London: Sage.

Cox, D. L., \& St. Clair, S. (2005). A new perspective on women's anger. Women \& Therapy, 28, 77-90.doi:: 10.1300/J015v28n02_06

Deffenbacher, J. L. (1999). Cognitive-behavioral conceptualization and treatment of anger. Journal of Clinical Psychology, 55, 295-309. doi: 10.1002/(SICI)10974679(199903)55:3<295::AID-JCLP3>3.0.CO;2-A

Digiuseppe, R., \& Tafrate, R. C. (2001). A comprehensive treatment model for anger disorders. Psychotherapy: Theory, Research, Practice, Training, 38, 262-271. doi: 10.1037/0033-3204.38.3.262

Duncan, B. L., \& Miller, S. D. (2000). The heroic client: Doing client-directed, outcomeinformed therapy. San Francisco, CA: Jossey Bass. 
Eatough, V., \& Smith, J. A. (2006). I feel like a scrambled egg in my head: An idiographic case study of meaning making and anger using interpretative phenomenological analysis. Psychology and Psychotherapy: Theory, Research and Practice, 79, 115-135. doi: $10.1348 / 147608305 \times 41100$

Elliott, R. (2010). Psychotherapy change process research: realizing the promise. Psychotherapy Research, 20, 123-135. doi: 10.1080/10503300903470743

Forgatch, M. S,, \& Patterson, G. R. (2010). Parental Management Training - Oregon Model: An intervention for antisocial behavior in children and adolescence. In J. R. Weisz \& A. E. Kazdin (Eds.), Evidence-based Therapies for Children and Adolescents, $2^{\text {nd }}$ ed. (pp. 159-178) New York:Guilford Press.

Friedlander, M. L., \& Phillips, S. D. (1984). Stochastic process analysis of interactive discourse in early counseling interviews. Journal of Counseling Psychology, 31, 139-148. doi: 10.1037/0022-0167.31.2.139

Hatcher, R. L., \& Gillaspy, J. A. (2006). Development and validation of a revised short version of the working alliance inventory. Psychotherapy Research, 16, 12-25. doi: $10.1080 / 10503300500352500$

Haynes, S. N., \& O’Brien, W. O. (2000). Principles of behavioral assessment: A functional approach to psychological assessment. New York: Plenum. 
Henry, W. P., Schacht, T. E., \& Strupp, H. H. (1990). Patient and therapist introject, interpersonal process, and differential psychotherapy outcome. Journal of Consulting and Clinical Psychology, 58, 768-774.

Hoener, C., Stiles, W. B., Luka, B. J., \& Gordon, R. A.(2012). Client experiences of agency in psychotherapy. Person-centered and Experiential Psychotherapies, 11, 64-82. doi:10.1080/14779757.2011.639460

Josephs, L., \& McLeod, B. A. (2014). A theory of mind-focused approach to anger management. Psychoanalytic Psychology, 31, 68-83.

Kannan, D., Henretty, J. R., Piazza-Bonin, E., Levitt, H. M., Coleman, R. A., BickerestTownsend, M., \& Mathews, S. S. (2011). The resolution of anger in psychotherapy: A task analysis. The Humanistic Psychologist, 39, 169-181.

Kramer, U., Berthoud, L., Keller, S., \& Caspar, F. (2014). Motive-oriented psychotherapeutic relationship facing a patient presenting with narcissistic personality disorder: a case study. Journal of Contemporary Psychotherapy, 44, 71-82. 
Laverty, S. M. (2003). Hermeneutic phenomenology and phenomenology: A comparison of historical and methodological consideration. International Journal of Qualitative Methods, 2, 21-35. Retrieved from http://creativecommons.org/licenses/by/2.0

McLeod, J. (2011). Qualitative research in counselling and psychotherapy. $2^{\text {nd }}$ ed. London: Sage.

McLeod, J., \& Balamoutsou, S. (2006). A method for qualitative narrative analysis of psychotherapy transcripts. In J. Frommer \& D. L. Rennie (Eds.), Qualitative psychotherapy research. Methods and methodology, $2^{\text {nd }}$ ed. ( pp. 128-152). Lengerich, Germany: Pabst Science Publishers.

Milbrath, C, Bauknight, R., Horowitz, M., Amoro, R., \& Sugahara, C. (1995). Sequential analysis of topics in psychotherapy discourse. A single-case study. Psychotherapy Research, 5, 199-217. doi: 10.1080/10503309512331331316

Moltu, C., Stefansen, J., Nøtnes, J. C., Skjølberg, Å., \& Veseth, M. (2017). What are "good outcomes" in public mental health settings? A qualitative exploration of clients' and therapists' experiences. International Journal of Mental Health Systems, 11, 12. doi: 10.1186/s13033-017-0119-5

Morrow-Bradley, C., \& Elliott, R. (1986). Utilization of psychotherapy research by practicing psychotherapists. American Psychologist, 41, 188-197. doi: 10.1037/0003-066x.41.2.188 
Norcross, J. C., Karpiak, C. P., \& Lister K. M. (2005). What's an integrationist? A study of self-identified and (occasionally) eclectic psychologists). Journal of Clinical Psychology, 61, 1587-1594. doi: 10.1002/jclp.20203

Oddli, H. W., McLeod, J., Reichelt, S., \& Rønnestad, M. H (2014). Strategies used by experienced therapists to explore client goals in early sessions of psychotherapy. European Journal of Psychotherapy and Counselling, 16, 245-266. doi:10.1080/3642537.2014.927380

Ornstein, P. H. (1999). Conceptualization and treatment of rage in self-psychology. Journal of Clinical Psychology, 55, 283-293. doi: 10.1002/(SICI)1097-4679(199903)55:3<283::AIDJCLP2>3.0.CO;2-I

Paivio, S.C. (1999). Experiential conceptualization and treatment of anger. Journal of Clinical Psychology, 55, 311-324. doi: 10.1002/(SICI)1097-4679(199903)55:3<311::AIDJCLP4>3.0.CO;2-Y

Pascual-Leone, A., Gilles, P., Singh, T., \& Andreescu, C. A. (2013). Problem anger in psychotherapy: An emotion-focused perspective on hate, rage, and rejecting anger. Journal of Contemporary Psychotherapy, 43, 83-92. doi: 10.1007/s10879-012-9214-8

Reichelt, S., Skjerve, J., \& McLeod, J. (2017a) Topic-focused analysis of verbal interaction in a case of integrative therapy with a young woman presenting with symptoms of depression. British Journal of Guidance and Counselling, 45, 42-55. Doi:

$10.1080 / 03069885.2016 .1167165$ 
Reichelt, S., Skjerve, J., \& McLeod, J. (2017b). Topic-focused analysis of verbal interaction in a case of integrative therapy for depression and emotional turmoil. Journal of Psychotherapy Integration. http://dx.doi.org/10.1037/int0000057

Rennie, D. L. (2012). Qualitative research as methodical hermeneutics. Psychological Methods, 17, 385-398. doi: 10.1037/a0029250

Rihacek, T., \& Roubal, J. (2017). The proportion of integrationists among Czech psychotherapists and counselors: A comparison of multiple criteria. Journal of Psychotherapy Integration, 27, 13-22. doi: 10.1037/int0000069

Rønnestad, M. (2009). An intensive process-out-come study of the interpersonal aspects of psychotherapy. Application for the Council of research. Oslo: Department of Psychology, University of Oslo.

Saini, M. (2009). A meta-analysis of the psychological treatment of anger: Developing guidelines for evidence-based practice. Journal of the American Academy of Psychiatry and the Law, 37, 473-488. Retrieved from https://www.ncbi.nlm.nih.gov/pubmed/20018996 
Skjerve, J., Reichelt, S., \& McLeod, J. (2016). Topic change processes in psychotherapy: a case study approach. Qualitative Research in Psychology, 13, 271-288. Doi: $10.1080 / 14780887.2016 .1196405$

Stewart, R. E., Stirman, S. W., \& Chambless, D. L. (2012). A qualitative investigation of practicing psychologists' attitudes toward research-informed practice: Implications for dissemination strategies. Professional Psychology: Research and Practice, 43, 100-109. doi: $\underline{10.1037 / \mathrm{a} 0025694}$

Stiles, W. B. (2002). Assimilation of problematic experiences. In J. C. Norcross (Ed.), Psychotherapy relationships that work: Therapist contributions and responsiveness to patients (pp. 357-365). New York: Oxford University Press. Stiles; W. B. (2007). Theorybuilding case studies of counselling and psychotherapy. Counselling and Psychotherapy Research, 7, 122-127. doi: 10.1080/14733140701356742

Thoma, N. C., \& Cecero, J. J. (2009). Is integrative use of techniques in psychotherapy the exception or the rule? Results of a national survey of doctoral-level practitioners. Psychotherapy: Theory, Research, Practice, Training, 46, 405-417..doi:10.1037/a0017900

Tracey, T. J. (1985). Dominance and outcome: A sequential examination. Journal of Counseling Psychology, 32, 119-122. doi: 10.1037/0022-0167.32.1.119 
Tracey, T. J., \& Ray, P. B. (1984). The stages of sucsessful time-limited counseling: An interactional examination. Journal of Counseling Psychology, 31, 13-27. doi: 10.1037/00220167.31 .1 .13

UU (2009). An intensive process-outcome study of the interpersonal aspects of psychotherapy. Application for the Council of Research.TT: Department of psychology, TT.

Wells, M. G., Burlingame, G. M., Lambert, M. J., Hoag, M. J., \& Hope, C. A. (1996). Conceptualization and measurement of patient change during psychotherapy. Development of the Outcome Questionnaire and Youth Outcome Questionnaire. Psychotherapy: Theory, Research, Practice, Training, 33, 275-283. doi: 10.1037.0033-3204.33.2.275

XYZ (2016). Topic-focused analysis of verbal interaction in a case of integrative therapy for depression and emotional turmoil. Published.

XYZ (2017). Topic-focused analysis of verbal interaction in a case of integrative therapy with a young woman presenting with symptoms of depression. Published.

YXZ (2016). Topic change processes in psychotherapy: A case study approach. Published. . 
